\title{
CAFÉ NAS ELEIÇÕES: O AMARGO E O DOCE NA GESTÃO ESTRATÉGICA DE UMA CAFETERIA
}

COFFEE IN THE ELECTIONS: THE BITTER AND THE SWEET IN THE STRATEGIC MANAGEMENT OF A COFFEE SHOP

Recebido em: 04/12/2018 • Aprovado em: 27/03/2019

Avaliado pelo sistema double blind review Editor Científico: Edson Sadao Iizuka DOI 10.13058/raep.2019.v20n2.1293

\section{BRENO DE PAULA ANDRADE CRUZ brenocruz@gastronomia.ufrj.br RENATO AUGUSTO DA SILVA MONTEIRO}

Universidade Federal do Rio de Janeiro

\section{RESUMO}

Esse caso verossímil à realidade política do Brasil na segunda década do século XXI aborda o impasse de um dos três sócios de uma cafeteria no Rio de Janeiro em relação a conflitos de outros dois sócios e seus posicionamentos políticos divergentes na cafeteria, influenciando o clima organizacional entre eles e o funcionário. A sociedade composta por Steven, João e Guilherme, iniciou-se com o aporte de capital de Steven, casado com Rosa - que é irmã e prima dos outros dois sócios. O conflito ideológico entre João e Guilherme se inflama e clientes também entram na discussão política na Café com Sonhos e se estende para as redes sociais virtuais por meio da hashtag \#cafecomsonhosleme. Nas plataformas digitais foram identificados alguns problemas relacionados à imagem e reputação da cafeteria, bem como reclamações sobre a diminuição da qualidade dos produtos. O fim da sociedade não é cogitado em função do alto investimento financeiro de Steven, e pelo fato de João e Guilherme terem na cafeteria suas rendas fixas mensais.

Palavras-Chave: Política; Planejamento Estratégico; Boicote do Consumidor.

\begin{abstract}
This true case about the political reality of Brazil in the second decade of the twenty-first century addresses a political impasse in a coffee shop in Rio de Janeiro (Brazil). It is about the conflicts between two owners regarding their different political positions, influencing the organizational climate and affecting the relationship among the partners and the employees. The partnership, which consists of Steven, John and Guilherme, began with the Steven's financial investment. Steven is married to Rosa (who is family-related to Guilherme and João). The ideological conflict between João and Guilherme is intense and clients also take part into the political discussion at Café com Sonhos. This political impasse was extended to virtual social media through the spread of the hashtag \#cafecomsonhosleme. Digital platforms have identified some problems related to the image and reputation of this coffee shop, as well as complaints about the decrease in product quality. Parting company is not being considered due to the high financial investment made by Steven and the fact that John and Guilherme get their monthly income only from the coffee shop.

Keywords: Politics; Strategic Planning; Consumer Boycott.
\end{abstract}




\section{O CASO}

\section{Amar, Empreender e Enriquecer}

Steven Mc'Onell é um jovem repórter esportivo americano que aos 26 anos desembarcou na cidade maravilhosa em 2016 para acompanhar alguns jogos de vôlei das equipes masculina e feminina dos Estados Unidos. Em sua passagem de quase 40 dias pelo Rio de Janeiro, além de se encantar pela cultura brasileira, Steven conheceu Rosa - com quem está junto até os dias atuais. Para aprender o português e se inteirar mais da cultura brasileira antes de apresentar seu currículo a alguns jornais impressos ou blogs de esportes, Steven decidiu abrir uma cafeteria no Leme com mais dois sócios: João e Guilherme.

João e Guilherme foram apresentados a Steven por Rosa, em função dos dois serem parte de sua família. João, 30 anos, é o irmão mais velho de Rosa, é administrador numa importante universidade privada no Rio de Janeiro (nota 5 no Enade). Guilherme, 27 anos, formado em Gastronomia por uma universidade pública carioca, é o primo no qual Rosa manteve um contato maior em toda sua vida. E Guilherme, que saiu do interior do estado do Rio de Janeiro para fazer o segundo grau na cidade maravilhosa, foi morar aos 15 anos na casa de Rosa e João. Ambos se gostam muito. Rosa sempre argumenta que João e Guilherme são seus irmãos, não havendo distinção de carinho, amor e respeito da parte dela para com eles.

Rosa e Steven são pessoas distantes de discussões sobre política - ele em função de ser americano e desconhecer o contexto social e econômico do país; e ela por ter sempre vivido discussões em jantares de uma família polarizada pelas ideologias políticas: esquerda e direita. Eles preferem se afastar desses conflitos, sobretudo em época de eleições. Para Rosa, "é melhor discutir religião e futebol do que política entre seus familiares".

Steven, declaradamente se mudou para o Brasil para se casar com Rosa. Para facilitar o visto e buscar a residência no Brasil, Steven resolveu investir seus dólares em um empreendimento gastronômico no Rio de Janeiro: a Cafeteria Café com Sonhos. O aporte inicial de capital foi algo em torno de 300 mil reais entre instalações, locação do imóvel, compra de 
utensílios de cozinha e capital de giro inicial. João e Guilherme participam com $25 \%$ desta sociedade. Cada um com seus conhecimentos construídos em suas formações acadêmicas, enquanto João organiza contas e gerencia o faturamento dentre outras tarefas administrativas, Guilherme é o responsável pelas questões relacionadas à produção do café (e seus derivados) e os doces da confeitaria. Nesse sentido, Guilherme monitora a qualidade dos grãos que chegam à cafeteria verificando se a torrefação pedida foi atendida pelo fornecedor; supervisiona o funcionamento da máquina de café (como a regulagem e a temperatura da água); bem como o armazenamento do leite e do chocolate utilizados na produção de cafés diferenciados como o capuccino, latte macchiato, cafés gelados e o café moca. Já Steven aparece na cafeteria todos os dias para abrir e fechar o estabelecimento e aproveita momentos com poucos clientes para jogar vôlei de praia e mergulhar na Praia do Leme.

\section{A Cafeteria Café com Sonhos}

A Café com Sonhos está situada no bairro do Leme, Zona Sul da cidade do Rio de Janeiro. O Leme é um bairro vizinho ao famoso bairro de Copacabana, tendo a mesma orla de mar, mesmo sendo um bairro com menor volume habitacional que Copacabana, recebe um grande volume de turistas por estar geograficamente próximo à ele. Ao mesmo tempo, por estar próximo à base militar da Urca e do Leme, tem a presença de aposentados que trabalharam no Exército Brasileiro ou que ainda estão em exercício. O bairro também possui duas favelas: os morros da Babilônia e Chapéu Mangueira. Com a falta de segurança vivida pela população carioca após os Jogos Olímpicos Rio 2016, essas duas comunidades em 2018 estão sendo alvo de constantes tiroteios entre traficantes e militares que compõem a intervenção militar presente na cidade. Tanto o morro da Babilônia quanto Chapéu Mangueira possuem alguns empreendimentos gastronômicos voltados para turistas nacionais e estrangeiros em função do "Favela Tour".

A Cafeteria Café com Sonhos surgiu em Agosto de 2017 e tem como missão "Oferecer cafés de qualidade aos clientes por meio da escolha de fornecedores que respeitem todos os envolvidos na cadeia de suprimentos; e doces sofisticados que realcem a culinária brasileira e o frescor da cidade 
maravilhosa". De maneira implícita nesta definição de missão, os sócios optam sempre que possível pela orientação gerencial para responsabilidade social corporativa (RSC). Uma dessas ações, por exemplo, foi a contratação de Ariel: um venezuelano transgênero que veio para o Rio de Janeiro construir uma vida com esperança de encontrar aqui menos preconceito e maior possibilidade de estabilização financeira.

Não existe no bairro nenhuma cafeteria que seja concorrente direta da Café com Sonhos. A videolocadora, que também servia cafés com uma pequena confeitaria fechou suas portas em 2018 e deu lugar a uma drogaria - visto que, segundo o dono da antiga videolocadora, "o Leme é um bairro de idosos e é lucrativo ter mais uma drogaria além das 4 já existentes em duas ruas paralelas com menos de 1,5 quilômetros de extensão". A única concorrência indireta que existe é a venda de alguns bolos e café no Supermercado Zona Sul - tradicional supermercado carioca voltado para um público AB.

Os principais doces são os sonhos e seus diferentes recheios. Parece haver um consenso entre os sócios que o sonho com brigadeiro de caju é um dos doces que possui potencial de crescimento no mercado - visto que é uma receita gourmet idealizada por Guilherme. O gastrônomo tem pensado em propor novos recheios de sonho com frutas típicas do Brasil como açaí e acerola. Guilherme já recebeu feedbacks positivos de clientes sobre uma degustação destes novos recheios e pensa em criar um mini-combo com estas três frutas brasileiras: cajú, acerola e açaí.

O bolo de tapioca com côco tem boa aceitação pelos clientes, possui alta demanda, contudo não tem possibilidade de aumentar a participação no mercado. O combo "Expressioca" (um café expresso simples + uma fatia de bolo de tapioca com côco) parece não se pagar em virtude dos problemas com o café já relatados por alguns clientes e a cafeteria ter que refazer o expresso (gerando um custo duplo). A abertura de uma academia de ginástica próxima ao estabelecimento tem fomentado a ideia de Steven em preparar bolos funcionais para clientes que saem da academia e não querem comer doces com alta densidade calórica. A torta integral de banana é um forte produto que poderá ganhar esse público, bem como o combo "Sonho Fit" - uma torta integral de banana com um frapê de Whey Protein. 


\section{Entendendo sobre Cafés Especiais}

O conceito de cafés especiais está ligado ao prazer proporcionado pela bebida, em que se destacam atributos específicos que dependem do produto, do processo de produção ou do serviço associado. Os atributos de qualidade de um café podem variar de acordo com suas características físicas, sua região, espécie (arábica e canéphora), tamanho do grão e até preocupações de ordem ambiental e social. A Associação Brasileira de Cafés Especiais (BSCA) considera que um café especial é aquele sem defeitos primários como pedras, paus ou café verde (REZENDE et al., 2011).

Os cafés especiais são puros (sem nenhuma mistura como milho ou qualquer outro cereal), da espécie arábica e conhecidos como de origem única. Uma das formas de aferir a qualidade do café é por meio da avaliação de especialistas credenciados pela Specialty Coffee Association of América (SCAA). Na SCAA, os cafés especiais são aqueles que em um escala de 0-100 obtém nota igual ou superior a 80 .

Todavia, um café especial pode ter uma boa classificação na SCAA, porém se sua extração e manuseio nas cafeterias não for realizado deforma adequada, o resultado da extração pode impactar a qualidade da bebida na xícara. Uma máquina de café expresso tem como objetivo extrair o potencial sensorial do café, aumentando as características de aroma e sabor tais como a doçura, acidez e as notas cítricas, frutadas ou florais. Assim, se a máquina não estiver bem regulada em relação à temperatura ( 90 a 96 graus ${ }^{\circ} \mathrm{C}$ ) e pressão ( 8,5 a 9,5 bar), o café obtido na xícara pode ser sub-extraído (ralo) ou super extraído (queimado e amargo), sem a formação da crema emulsão de óleos na superfície do café expresso que mantêm a temperatura e potencializa a percepção do aroma e sabor (CONCETTA; COUTO, 2013; DPASCHOAL, 2006).

Um café sub-extraído ou super-extraído está relacionado à moagem do grão (granulometria) - que é realizada pelo moinho de café. Em um café sub-extraído a granulometria pode estar grossa e no super-extraído muito fina. Em uma máquina de café expresso a pressão e a temperatura devem ser regularmente verificadas para se obter o café ideal com crema sem ser ralo, queimado ou amargo. Da mesma forma, para manter a qualidade de 
um café especial, algo que poucos empreendedores sabem é que a temperatura da xícara deve considerada; devendo a xícara estar aquecida para que não se perca o aroma e o sabor de um café especial.

\section{Política: Amor e Ódio?}

João é uma pessoa que se considera conservadora e de direita. Nas eleições de 2018 apoiou explicitamente o presidenciável Jair Bolsonaro; e, consequentemente, toda sua plataforma de governo. Guilherme se considera um jovem progressista de esquerda e declarou seu apoio político à chapa Lula-Haddad-Manuela. O problema que a Cafeteria Café com Sonhos enfrenta é o choque de ideologias que João e Guilherme têm, o que gera conflitos entre eles na frente de outros funcionários e clientes. O trecho a seguir retrata o estopim de suas divergências políticas na cafeteria:

Guilherme respondendo um áudio no grupo de amigos no WhatsApp - "É um absurdo cancelarem a candidatura do Lula. Nunca na história deste país houve tanto investimento em educação e projetos sociais. Vários brasileiros deixaram a linha da miséria. Se eu estudei em universidade pública foi porque teve o Reuni! É, galera... se vem o Bolsominion aí, vai ser uma guerra com todo mundo com arma. O feminicídio aumentará!"

João escuta a gravação do audio e intervém - "O Brasil não vai pra frente por causa disso! São pessoas como você que votam no presidiário Lula é que estão afundando esse país! Essa galera da esquerda só quer saber de fumar maconha e defender bandido. Bandido bom é bandido morto! Vocês ficam com esse mimimi com bandido! Tem que fuzilar mesmo!"

Guilherme se exalta e intervém - "É João... me admira a sua falta de empatia com o ser humano! Se combate violência com políticas públicas, não com arma!"

João intervém - "Quero ver você chegar aqui amanhã de manhã depois de ter seu celular e sua carteira roubados e você vir falar de direitos huma- 
nos! Quero ver você não ter vontade de matar um bandidinho de 17 anos que colocou a arma na sua cabeça - como aconteceu comigo ano passado! Não venha me falar disso porque você não teve uma arma apontada para sua cabeça!"

Percebendo que o clima estava esquentando e alguns clientes já começavam a se mexer nas mesas, o barista venezuelano Ariel chega e oferece dois copos de água para os sócios e delicadamente pede para que os dois percebam que alguns clientes estavam olhando. Um cliente, de aproximadamente 40 anos interfere na discussão e levanta o tom de voz:

Cliente 1 - "Ei, me diga uma coisa. Desde quando que esse nazista está trabalhando aqui? Quero saber os dias e horários porque eu não quero voltar aqui e dar de cara com esse ser! Meu café foi $\mathrm{R} \$ 8,90$, mas estou deixando aqui em cima da mesa $R \$ 10,00$ porque não quero ter que chegar perto desse cara! E agora eu faço meu boicote a essa cafeteria. Vou falar para todos meus vizinhos e amigos para não aparecerem aqui porque eles, assim como eu fiz agora, estariam financiando um nazista!"

O cliente 1 jogou o dinheiro em cima da mesa e começou a levantar-se, quando já na porta de saída do estabelecimento foi repreendido pelo cliente 2, um senhor de aproximadamente 65 anos de idade:

Cliente 2 - "Se ele não volta aqui mais, eu volto! Quer dizer que agora somos nazistas por apoiar Bolsonaro? Esse bando de ptralhas que arruinou o Brasil! O Brasil só tem jeito com uma nova ditadura! E vocês podem ficar com os R\$10,00 dele de gorjeta para vocês e coloque o café daquele esquerdopata na minha conta! Eu vou pagar! Afinal, esses pobres comunistas não têm dinheiro e deveriam ir pra Cuba!"

Atônitos com aquela situação, João, Guilherme e Ariel se olharam sem saber o que fazer. Steven entra na cafeteria no exato momento em que o senhor termina suas palavras e acaba percebendo pelos olhares de 
outros clientes, dos seus sócios e de Ariel que algo de estranho acontecia naquele final de noite. Ariel se esquiva de dar respostas por ser o lado mais fraco naquela situação e por também ser estrangeiro. João e Guilherme entendem que houve excessos e fogem de explicações mais detalhadas a Steven argumentando que depois eles conversariam ao fechar a Café com Sonhos.

Algumas horas depois, clientes que não estavam no momento da discussão excedem o horário de fechamento do estabelecimento e os três sócios e o funcionário têm que sair com pressa em função do avançado horário na noite. No dia seguinte, pelo grupo do WhatsApp, Steven questiona aos seus sócios o que tinha ocorrido naquela noite quando entrou. Ninguém respondeu. Steven liga para Ariel para saber o que tinha acontecido.

Steven - "Alô. Tudo bem? Pode falar agora?"

Ariel - "Sim, senhor Steven. Posso falar!"

Steven - "O que aconteceu na cafeteria ontem?"

Ariel - "Ahn... uma discussão..."

Steven - "Com você? Com o cliente? Você falou coisa errada?"

Ariel - "Não, senhor Steven."

Steven - "Então o que houve?"

Ariel - "Não quedo confortável em hablar sobre isto... Mi trabajo... necesito... mi país ahora não és um momento bueno la economia. No posso perder mi trabajo".

Steven - "Mas se você não fez nada de errado. Tell me...".

Ariel - "Houve una discussion sobre política entre João e Guilherme e os clientes se irritaram".

Steven - "Thank you very much! I could suppose it would happen...".

Ariel - "Perdon... no compreendo...".

Steven - "Desculpa... pensei fast em Inglês - minha mother language. Eu sabia que isso iria acontecer um dia na cafeteria. Nas reuniões da família de Rosa eles sempre discutiam política de maneira agressiva. Mas aqui na cafeteria não!”. 


\section{\#OqueHouve?}

Steven, como jornalista de formação, desligou o telefone e entrou no Twitter, no Facebook e no Instagram para verificar a hashtag \#cafecomsonhosleme e começou a fazer o que ele fazia uma vez a cada duas semanas: monitorar o que os clientes falavam sobre os produtos e serviços da cafeteria. Para a surpresa dele, Steven achou para os últimos 15 dias, 35 compartilhamentos no Twitter das pessoas que eram amigas de um cliente e outras 18 potagens referentes à outro cliente. As principais mensagens se encontram no Quadro 1.

\section{Quadro 1 Posts no Twitter}

\section{Nome do \\ Cliente no \\ Post \\ Twitter}

$\begin{array}{cl}\text { João } & \text { "Vocês perderam a confusão na \#cafecomsonhosleme na } \\ \text { Andrade } & \begin{array}{l}\text { noite de ontem. Baixaria total dos sócios e dos clientes por } \\ \text { causa de política!" }\end{array} \\ \text { Rosilene } & \text { "A xícara da \#\#cafecomsonhosleme veio suja e com marca } \\ \text { Andrade } & \text { de batom, sabãozinho ia bem, hein!?" } \\ \text { Jéssica } & \text { "Mais amor, menos política \#cafecomsonhosleme” } \\ \text { Sangalo } & \text { "A partir de hoje eu boicoto a \#cafecomsonhosleme por- } \\ \text { Júnior } & \text { que um dos sócios vota e apóia aquele ser que nem merece } \\ \text { Silva } & \text { ser nomeado!" } \\ \text { Enzo } & \text { "Sinistro o tiozinho na \#cafecomsonhosleme ontem! Ele } \\ \text { Rinaldi } & \text { destruiu um esquerdopata e ainda pagou o café dele! Lo- } \\ \text { Clara } & \text { "Ololol” sonho de caju é de comer virando os olhos! Tenho que } \\ \text { Livadias } & \text { parar de comer para não engordar! Mas eu não consigo!" } \\ \text { Mônica } & \text { "o café não formou a crema. Café sem crema é igual ovo } \\ \text { D’Avilla } & \text { sem gema, não dá sabor!” }\end{array}$




\begin{tabular}{|c|c|}
\hline $\begin{array}{l}\text { Juliana } \\
\text { Moreira }\end{array}$ & $\begin{array}{l}\text { "\#cafecomsonhosleme tá apoiando o PT? Não entro lá } \\
\text { nunca mais!" }\end{array}$ \\
\hline $\begin{array}{l}\text { Ulisses } \\
\text { Fortunato }\end{array}$ & $\begin{array}{l}\text { "Pedi um cappucino e veio um fracotino muito leite e pou- } \\
\text { co café, conte com o bom humor do barista, o \#cafedosso- } \\
\text { nhos já foi dos sonhos... ahhhhh... pesadelo!" }\end{array}$ \\
\hline $\begin{array}{c}\text { Paloma } \\
\text { Velvet }\end{array}$ & $\begin{array}{l}\text { "Meu pai me disse que na \#cafecomsonhosleme você ga- } \\
\text { nha um café se discutir política. Você só tem que agradar } \\
\text { um dos sócios.... tô morto! rs" }\end{array}$ \\
\hline $\begin{array}{l}\text { Kriger } \\
\text { Boladão }\end{array}$ & $\begin{array}{l}\text { retwitt de Paloma "Meu pai me disse que na \#cafecomso- } \\
\text { nhosleme você ganha um café se discutir política. Você só } \\
\text { tem que agradar um dos sócios.... tô morto! rs" }\end{array}$ \\
\hline $\begin{array}{l}\text { Muleke do } \\
\text { Leme }\end{array}$ & $\begin{array}{l}\text { retwitt de Paloma "Meu pai me disse que na \#cafecomso- } \\
\text { nhosleme você ganha um café se discutir política. Você só } \\
\text { tem que agradar um dos sócios.... tô morto! rs" }\end{array}$ \\
\hline $\begin{array}{l}\text { Nandinha } \\
\text { Tricolor }\end{array}$ & $\begin{array}{l}\text { retwitt de Paloma "Meu pai me disse que na \#cafecomso- } \\
\text { nhosleme você ganha um café se discutir política. Você só } \\
\text { tem que agradar um dos sócios.... tô morto! rs" }\end{array}$ \\
\hline $\begin{array}{l}\text { Fernanda } \\
\text { Harumi }\end{array}$ & $\begin{array}{l}\text { "Tem algum vídeo da briga rolando? Compartilha no } \\
\text { Zap..." Em resposta ao post de João Andrade }\end{array}$ \\
\hline Ivete Cruz & $\begin{array}{l}\text { eve ter sido a moagem grossa } \\
\text { quada." }\end{array}$ \\
\hline $\begin{array}{c}\text { Joyce } \\
\text { Bouateaux }\end{array}$ & $\begin{array}{l}\text { "Ontem tomei café na \#cafecomsonhosleme no finalzinho } \\
\text { da noite e o sonho não estava tão bom como é. Perdeu } \\
\text { minha preferência. }\end{array}$ \\
\hline $\begin{array}{l}\text { Yasmim } \\
\text { Fraga }\end{array}$ & "O sonho com brigadeiro de caju continua maravilhoso!" \\
\hline Yan Curral & $\begin{array}{l}\text { Em resposta ao post de Joyce: "Os sócios não estavam nada } \\
\text { doces ontem... presenciei uma discussão de sócios e clien- } \\
\text { tes por causa de política. Aff..." }\end{array}$ \\
\hline $\begin{array}{l}\text { Gabriela } \\
\text { Andrade }\end{array}$ & $\begin{array}{l}\text { Em resposta ao post de Joyce: "Comida tem que ser feita } \\
\text { com amor. Se tinha alguém azedo, passou pro sonho... que } \\
\text { virou pesadelo! ahahahaha" }\end{array}$ \\
\hline
\end{tabular}




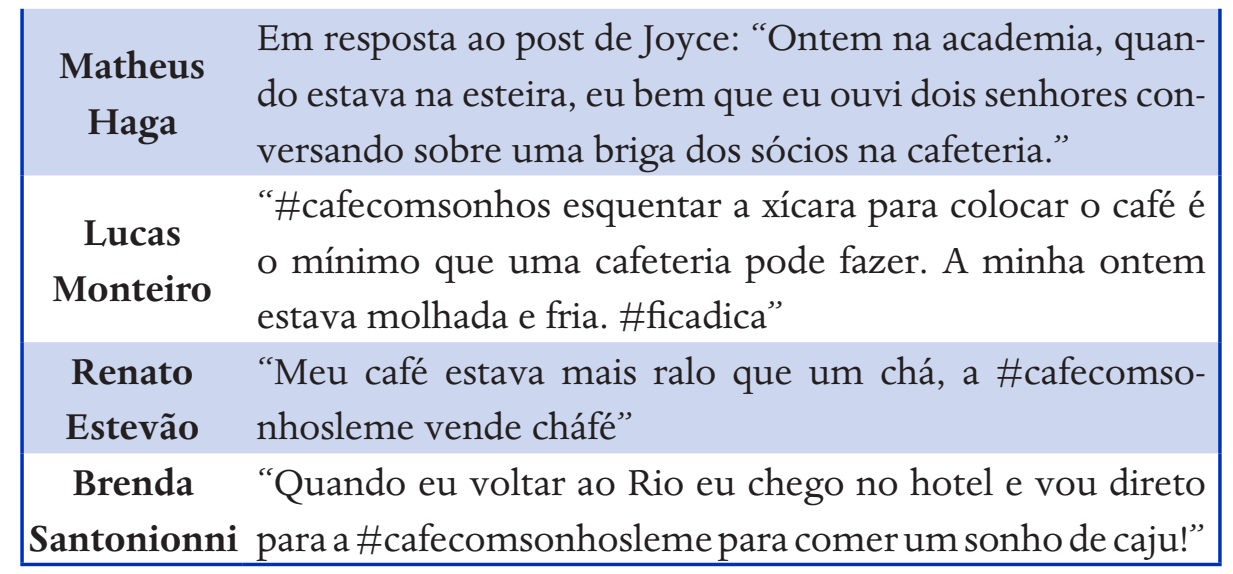

Fonte: Elaboração dos autores.

\section{E agora?}

Steven fez o print de todos esses comentários que encontrou no Twitter, Facebook e Instagram e adicionou as imagens no grupo dos sócios e pediu explicações a João e Guilherme. Por 30 minutos ninguém respondeu nada - embora os dois sócios tivessem visualizado as mensagens. Sem resposta, Steven gravou um áudio:

Steven - "Brothers, eu não investi meu dinheiro no Brasil para vocês ficarem discutindo política e assustarem os clientes! Olha o que estão comentando nas redes sociais sobre nossa empresa! E a nossa reputação no bairro? Será que daqui a pouco vai ter manifestação na frente da Café com Sonhos para apoiarem políticos? Vocês sabem quem é Lucas Monteiro, né? O Guilherme com certeza deve saber! Ele é um dos mais importantes baristas no Brasil e criticou nossa cafeteria no Twitter! Erro básico de quem trabalha com café! Foi erro do Ariel ou foi erro de vocês que criaram esse clima horrível de trabalho pra ele? Já não basta a crise humanitária que a Venezuela está passando e esse coitado aqui tendo que escutar dois patrões malucos discutindo política na frente dele e dos clientes? Vocês têm noção do clima ruim que vocês geraram para ele e para os clientes? E se os clientes não voltarem? Vamos ter que desfazer a sociedade?!” 
Guilherme responde no grupo: - "Eu estava gravando uma mensagem de áudio quando ele veio enfiar o nariz onde não foi chamado! Eu tava de boas..."

João enfatiza: - "Steven, você sabe que o país está desse jeito por causa dos governos de esquerda nos últimos anos..."

Steven grava outro áudio: - "Vocês não são moleques - como se diz aqui na cidade de vocês. Eu que sou gringo já aprendi a viver aqui. Eu fiz pesquisa para encontrar os melhores fornecedores de café neste país. Verifiquei a cadeia de suprimentos de cada fornecedor de café Bourbon Amarelo da espécie arábica, produzido acima de 1000 metros de altitude no Caparaó mineiro para ter certeza que os funcionários tinham condições boasde trabalho e que não havia trabalho escravo. Fui no sul de Minas e no Espírito Santo visitar fazendas para escolher a que seria fornecedora do grão.

Steven grava outro áudio: - Contratei um provador Q Grader, juiz certificado pela Speciality Coffee Association of America (SCAA), uma renomada associação de cafés especiais norte americana que surgiu na década de 1980 para certificar a qualidade dos cafés. Eu paguei para que o provador avaliasse os cafés das fazendas visitadas, conferindo nota para dos grãos. Assim a gente teriaos melhores fornecedores de fazendas de grãos especiais de café. Investi em cursos específicos de café para o Guilherme na Semana do Fazendeiro na Universidade Federal de Viçosa. Deixei mais de 50 mil reais disponíveis nas mãos do João para despesas iniciais da cafeteria. E o que vocês fazem? Brigam por política na frente do funcionário e dos clientes.

João e Guilherme ouvem o áudio e não respondem; Steven continua dez minutos depois do silêncio.

Steven - "Eu, como jornalista de formação nos Estados Unidos sei a importância da reputação de uma empresa e vocês, como sócios, ao invés de alavancar a empresa positivamente oferecendo bons produto e serviços, 
acham que isso é jantar de família e ficam discutindo política. Vai fazer monografia no curso de Ciências Políticas ao invés de ser sócio em uma cafeteria. Suas ideias e nem seus votos de presidente vão mudar este país!" Foca no bom atendimento! Foca no relacionamento, hospitalidade e gentileza com os clientes. A briga de vocês já está tendo resultado na qualidade dos doces e isso vem impactando as vendas - que também estão caindo. Já viram as piadinhas que o pessoal fez? De que adianta ser formado em Gastronomia e não fazer doces bons porque o outro sócio irrita aquele que põe a mão na massa? De que adianta ter uma máquina italiana de café de $\mathrm{R} \$ 25.000,00$ se o café não está sendo moído na regulagem correta? Vi no Twitter que a moagem do café expresso está muito fina. A granulometria precisa ser média para que seja possível produzir a crema do café; que, como vocês sabem, deve possuir cor avelã. Alguns de nossos clientes são consumidores gourmet e não adianta levar na mesa uma água rala e escura que não vai colar. Vamos perder o que estamos começando a construir. Por que o funcionário tem que servir o café, receber o pagamento, moer o grão e ainda ter que separar discussão dos sócios?”

\section{Um café e novos sonhos para adoçar a Café com Sonhos}

A questão familiar que envolve Steven não é tão simples de ser resolvida em função de envolver dois sócios que têm uma relação afetiva muito sólida com sua esposa - motivo pelo qual ele se mudou para o Brasil. Romper com um dos sócios traria resultados não somente operacionais para a cafeteria, mas, também, no seu relacionamento com a esposa. E, nós brasileiros, como aponta estudiosos como Roberto Da'Mata somos um povo que valoriza muito as relações pessoais (inclusive no trabalho).

Mesmo que não tenha uma concorrência direta, Steven precisa pensar algumas ações para: (a) evitar que novas discussões como a que ocorreu influencie o clima entre os sócios e os funcionários; (b) reconquistar clientes que explicitaram em suas redes sociais virtuais a intenção de boicotar a Café com Sonhos; (c) fortalecer a reputação da cafeteria em relação às suas ações de responsabilidade social corporativa - seja dentro ou fora das comunidades circunvizinhas ao Leme; e, (d) retomar a produção de doces sofisti- 
cados com qualidade e o requinte de um chefe de cozinha especializado em confeitaria; (e) conscientizar colaboradores da atenção e correto manuseio na extração do café expresso para que mantenha/explore o potencial e a qualidade dos grãos selecionados desde os fornecedores. O que você faria para ajudar um gringo nesta situação que envolve família e negócios? 


\section{NOTAS DE ENSINO}

\section{Resumo do Caso}

Esse caso verossímil à realidade política do Brasil na segunda década do século XXI aborda o impasse de um dos três sócios de uma cafeteria na cidade do Rio de Janeiro (RJ) em relação aos conflitos de outros dois sócios e seus posicionamentos políticos divergentes no estabelecimento, influenciando o clima organizacional entre eles e o funcionário. A sociedadeque é composta por Steven, João e Guilherme, iniciou-se com o aporte de capital de Steven, casado com Rosa - que é irmã e prima dos outros dois sócios. O conflito ideológico entre João e Guilherme se inflama e clientes também entram na discussão política na cafeteria e a discussão se estende para as redes sociais virtuais por meio da hashtag \#cafecomsonhosleme. Nas plataformas digitais foram identificados alguns problemas relacionados à imagem e reputação da cafeteria, bem como reclamações sobre a diminuição da qualidade dos produtos (cafés e doces). Não é visualizado o fim da sociedade em função do alto investimento financeiro de Steven e pelo fato de João e Guilherme terem na cafeteria suas rendas fixas mensais.

\section{Propósito Geral do Caso}

O presente caso tem como objetivo discutir os problemas gerenciais de um dos sócios a partir da dicotomização política existente entre outros dois sócios e que trouxe grandes problemas à Cafeteria Café com Sonhos. A dicotomização política no Brasil na segunda década do século XXI é uma realidade e recentemente tem sido abordada nos estudos em comportamento do consumidor (CRUZ, 2018; CRUZ; ROSS, 2016; CRUZ, 2016). Dessa forma, trazer uma realidade latente à luz de um empreendimento gastronômico contribui na relevância deste caso.

Especificamente em relação à cafeteria, a Gastronomia enquanto área de conhecimento tem sido construída no Brasil e sua sub-área de Gestão nos cursos de bacharelado e tecnológos se faz presente - o que permite a utilização deste caso tanto em cursos de graduação em Administração 
quanto em cursos de Gastronomia. Além disso, muitos dos novos negócios estão relacionados ao setor da Gastronomia. Nos dois cursos, o caso pode ser utilizado para discutir questões relacionadas ao Planejamento Estratégico e Marketing, tendo como temas transversais: responsabilidade social corporativa; imagem e reputação Corporativa; boicote do consumidor; e, monitoramento de redes sociais virtuais.

Embora o caso apresente informações específicas sobre uma cafeteria, seus processos e especificadades relacionadas ao segmento de café, sua análise permite aos estudantes uma reflexão ampla sobre: (a) o contexto político como variável do macroambiente; (b) as relações pessoais e o clima organizacional influenciando nos processos internos do microambiente e a qualidade de produtos e serviços; (c) como as redes sociais virtuais podem ser utilizadas para monitorar a qualidade dos produtos e serviços oferecidos por meio de hashtags; (d) a importância de inserir a discussão sobre responsabilidade social corporativa à luz de pequenas empresas; (e) como o posicionamento de sócios ou proprietários referentes a temas complexos podem influenciar o boicote do consumidor.

Assim, sugerimos que este caso seja utilizado em uma disciplina de Planejamento Estratégico em função de entendermos que o (a) discente precisa de um conhecimento prévio das áreas de Gestão de Pessoas, Marketing e Produção e Operações para pensar os problemas e questões que são apresentados. É ideal que na disciplina de Planejamento Estratégico seja abordada a orientação para Responsabilidade Social Corporativa à luz da Teoria dos Stakeholders e não como ações assistencialistas ou filantrópicas, conforme já discutem alguns autores (CRANE et al., 2008).

\section{Preparação para o Caso}

Este caso pode ser resolvido em 4 horas - aula. É importante que o (a) professor (a) não tenha se manifestado em relação à sua ideologia política em qualquer contato prévio com os (as) estudantes para que eles (as) não ofereçam a resposta que seja aquela que seria a ideal para agradar o (a) docente. Se houve posicionamento político do (a) docente a favor (ou contra) a esquerda ou a direita no Brasil, não se recomenda este caso pelo fato de 
não se ter um ambiente sem direcionamento político por parte do docente ou da instituição. Adicionalmente, outras informações são relevantes:

- Sugere-se que este caso seja aplicado ao final de uma disciplina para que assim possam ser trabalhadas as teorias. Adicionalmente, em um campo com tantas discussões nos últimos anos, o (a) docente tem que perceber ao longo do semestre se existem sujeitos bélicos que não estariam ainda preparados para uma discussão que envolve ideologia e conhecimentos gerenciais.

- A leitura prévia do caso deve ser realizada antes da aula.

- Se possível, seria interessante que o (a) educador (a) perceba que, se em cada grupo existe pelo menos uma pessoa que se declare de esquerda e outra que se declare de direita. Esta alternativa pode trazer maior realidade para a situação problema deste caso. Tente identificar no decorrer da disciplina perfis de estudantes que são conciliadores e tente colocá-los em um grupo no qual possa ter algum (a) estudante mais agressivo (a).

\section{Objetivos Educacionais}

- Reforçar com os participantes conceitos de Planejamento Estratégico, tais como: Posicionamento de Mercado, Concorrência, Matriz BCG, Modelo das Cinco Forças Competitivas de Porter e Macro e Micro ambientes;

- Fomentar o interesse em discutir conflitos presentes em organizações familiares e as dificuldades relacionadas às decisões do negócio que podem impactar nas relações familiares;

- Discutir a importância de se entender o macro ambiente - especificamente a dicotomia ideológica entre cidadãos de esquerda de direita e como isso pode influenciar no clima organizacional e na relação com os clientes;

- Fomentar a discussão sobre boicote do consumidor e suas motivações (política, ambiental, social, religiosa, relacional, econômica e de minorias); 
- Abordar de maneira sistêmica do conceito de Responsabilidade Social Corporativa por meio dos exemplos 'diversidade' e 'favelas';

- Oferecer a reflexão sobre empreendimentos gastronômicos e segmentação de mercado.

\section{As Fontes Básicas de Pesquisa para o (a) Discente}

Os textos apresentados a seguir servem de auxílio para (i) a construção do conteúdo na disciplina (no caso do livro didático); e (ii) o entendimento da política como variável que pode influenciar o consumidor a realizar o boicote a uma empresa, marca, produto ou serviço em função da desconexão de ideologia política da empresa e do consumidor (no caso do artigo).

CHIAVENATO, I..; SAPIRO, A. Planejamento Estratégico: Fundamentos e Aplicações. Rio de Janeiro: Elsevier, 2014.

CRUZ, B. de P. A. Boicote Político. In: ENANGRAD, 29, 2018, FECAP. São Paulo-SP. Anais XXIX Enangrad. São Paulo: Angrad, Outubro 2018, 1-15. Disponivel em: http://www.enangrad.org.br/pdf/2018_ENANGRAD25.pdf. Acesso em: 02 Out. 2018.

\section{Questões para discussão}

As questões apresentadas a seguir devem ser trabalhadas de maneira assertiva de modo que a discussão não se oriente para a polarização esquerda $\mathrm{x}$ direita na política; e, sim, sobre os assuntos que versam a aula.

- É possível identificar um produto estrela à luz da Matriz BCG? Quais os argumentos para indicá-lo?

- Quais forças seriam mais importantes a serem consideradas no modelo das Cinco Forças Competitivas de Porter? Por quê?

- Como resgatar a percepção de alguns consumidores da Café com Sonhos sobre a qualidade dos produtos oferecidos? 
- Como a Café com Sonhos pode gerenciar sua reputação? Quais estratégias pontuais poderiam ser usadas para trabalhar as ironias, reclamações e posicionamentos e consumidores e clientes em potencial no Twitter?

- O que pode ser realizado para diminuir os conflitos entre os sócios e melhorar o clima organizacional?

- Quais ações relacionadas à Responsabilidade Social Corporativa a Café com Sonhos poderia reafirmar ou instituir junto aos moradores dos morros Chapéu Mangueira e Babilônia?

- Como evitar que futuros clientes boicotem a Café com Sonhos?

\section{Alternativas para Análise do Caso}

Trabalhamos aqui com a sustentabilidade do negócio. Ou seja, não pode ser apresentado aos (as) discentes a possibilidade de finalização da sociedade. O fim da sociedade poderia aumentar ainda mais a tensão familiar que já existe entre os primos, podendo inclusive interferir no casamento de Steven e Rosa. Logo, o fim da sociedade não se apresenta como alternativa. Abaixo listamos três alternativas que concluímos ser relevantes para direcionar uma solução para o caso, podendo ser trabalhadas isoladamente ou em conjunto:

- Foco na Operação da Cafeteira Expresso - o clima gerado no ambiente da cafeteria tem afetado diretamente a concentração de Ariel (o que pode estar repercutindo na qualidade da bebida entregue ao cliente). A regulagem da máquina pode ser uma das principais ações para resolver o problema citado por alguns clientes no Twitter.

- Evitar o Posicionamento Político - a dicotomização para uma empresa não é algo que seja interessante - ainda mais quando se pensa em ideologia política. Nesse sentido, uma das alternativas é eliminar assuntos relacionadas à política no cotidiano da Café com Sonhos. Isso evitaria o desgaste entre os sócios, uma maior 
concentração do funcionário que faz as bebidas e não geraria discussão entre os clientes.

- Repensar o Portfólio de Doces e Combos - é evidente que o Sonho com recheio de caju é o produto estrela da Café com Sonhos - isso pode ser verificado nos twitts dos consumidores, todavia, existe também um produto Abacaxi (Expressioca). Concomitantemente, uma nova variável foi inserida no macroambiente: a abertura de uma academia de ginástica. Dessa forma, uma possível orientação para um nicho de mercado possa ser pensada a partir de produtos que sejam funcionais.

\section{Referências Complementares Sugeridas para Docentes}

O Quadro 2 apresenta uma relação de referências complementares que podem auxiliar docentes na construção teórica do caso. A referência é seguida de uma nota explicativa do motivo da indicação. Por exemplo, no caso da Responsabilidade Social Corporativa, no decorrer dos anos muitos autores brasileiros focaram suas análises nas ações filantrópicas ou assistencialistas das empresas. Ou seja, quando no caso apresentamos o contexto de um funcionário transgênero, por exemplo, discutimos RSC à luz da Teoria dos Stakeholders - visto que o setor da Gastronomia, assim como no Entretenimento e na Beleza, recebe em seus postos de trabalho pessoas transgêneras. 
Quadro 2 Sugestão de referências adicionais para docentes

\begin{tabular}{|c|c|}
\hline Referência & Motivo de Indicação \\
\hline $\begin{array}{l}\text { CRUZ, B. de P A. Curtir, Comentar, Com- } \\
\text { partilhar: Redes Sociais e TV no Brasil. } \\
\text { Curitiba: Editora CRV, } 2016 .\end{array}$ & $\begin{array}{l}\text { Discute o fenômeno das redes sociais } \\
\text { no Brasil à luz da influência da tele- } \\
\text { visão, servindo como material para } \\
\text { ajudar compreender questões políti- } \\
\text { cas e sociais do consumidor no âmbi- } \\
\text { to da indústria do entretenimento. }\end{array}$ \\
\hline $\begin{array}{l}\text { CRANE, A., MCWILLIANS, A., MAT- } \\
\text { TEN, D., MOON, J., SIEGEL, D. S. The } \\
\text { Oxford handbook of corporate social respon- } \\
\text { sibility. New York: The Oxford Universi- } \\
\text { ty Press, } 2008 .\end{array}$ & $\begin{array}{l}\text { Apresenta o conceito de Respon- } \\
\text { sabilidade Social Corporativa, sem } \\
\text { que o foco seja em ações filantrópi- } \\
\text { cas ou assistencialistas. }\end{array}$ \\
\hline $\begin{array}{l}\text { HÖRISCH, J.; FREEMAN, R. Ed- } \\
\text { ward; SCHALTEGGER, S. Applying } \\
\text { Stakeholder Theory in Sustainability } \\
\text { Management: Links, Similarities, Dis- } \\
\text { similarities, and a Conceptual Frame- } \\
\text { work. Organization and Enviroment, } \\
\text { v. } 27, \text { n. 4, 2014. DOI: https: / / doi. } \\
\text { org/10.1177 / 1086026614535786 }\end{array}$ & $\begin{array}{l}\text { O texto compara a Teoria dos } \\
\text { Stakeholders com Gestão Susten- } \\
\text { tável, apresentando que os desafios } \\
\text { da sustentabilidade (que envolve a } \\
\text { noção de RSC) dependem de me- } \\
\text { canismos inter-relacionados como } \\
\text { educação, regulação e sustentabili- } \\
\text { dade baseada no valor criado para } \\
\text { os stakeholders. }\end{array}$ \\
\hline $\begin{array}{l}\text { BARBERO, E. R.; MARCHIANO, M. } \\
\text { Stakeholders or Shareholders? Board } \\
\text { members' personal values and cor- } \\
\text { porate identity. Revista Brasileira de } \\
\text { Gestão de Negócios, v. 18, n. 61, 348-369 } \\
\text { (jan./ mar.). 2016. DOI: https: / doi. } \\
\text { org/10.7819/ rbgn.v18i61.3020 }\end{array}$ & $\begin{array}{l}\text { Identifica que empresas que se } \\
\text { orientam para os stakeholders apre- } \\
\text { sentam em seus quadros de conse- } \\
\text { lho consultivo conselheiros menos } \\
\text { individualistas e mais orientados } \\
\text { para os interesses dos atores envol- } \\
\text { vidos. }\end{array}$ \\
\hline $\begin{array}{l}\text { ARGENTI, P. A. Comunicação empresa- } \\
\text { rial. Rio de Janeiro: Campus Elsevier, } \\
2005 .\end{array}$ & $\begin{array}{l}\text { Apresenta a diferença entre Identida- } \\
\text { de, Imagem e Reputação na Comuni- } \\
\text { cação Empresarial, bem como siste- } \\
\text { matiza informações sobre Gestão de } \\
\text { Crise em organizações privadas. }\end{array}$ \\
\hline
\end{tabular}


RODRIGUES, J.; MIYAHIRA, N. N.; NASCIMENTO, F; MARINHO, B. de

L. Por que Marcas Corporativas? A Percepção de Executivos Brasileiros sobre os motivos para adotar Corporate Branding. Revista Eletrônica de Administração, v. 23, Dec. 2017. DOI: http: / / dx.doi. org/10.1590/1413-2311.154.57163

HETZE, K. Effects on the (CSR) Reputation: CSR Reporting Discussed in the Light of Signalling and Stakeholder Perception Theories. Corporate Reputation Review, v. 19, n. 3, p. 281-296, 2016. DOI: https: / / doi.org/10.1057/s41299-0160002-3

FRIEDMAN, M. Consumer boycotts: A conceptual framework and research agenda. Journal of Social Issues, v. 47, n. 1, 149-168, 1991.

CRUZ, B. de P. A. Social Boycott. Revista Brasileira de Gestão de Negócios, v. 19, n. 63, 5-29 (jan./mar.). 2017.

FERREIRA, R. da S. A informação social no corpo travesti (Belém, Pará): uma análise sob a perspectiva de Erving Goffman. Ci. Inf., Brasília, v. 38, n. 2, p. 35-45, 2009. Disponível em: $<$ http: / / dx.doi.org/10.1590/S010019652009000200003>. Acesso em: 03 Set. 2018.
Aborda, entre outros conceitos, como a reputação e a imagem podem possibilitar vantagem competitiva.

Discute o impacto da responsabilidade social corporativa na reputação de uma empresa.

Discute de maneira o boicote do consumidor, sendo um dos primeiros trabalhos a propor uma agenda de pesquisa.

A parte teórica do trabalho contribui para que se entendam os tipos de boicote listados na literatura em comportamento do consumidor

Discute a inserção de pessoas transgêneras no mercado de trabalho e as dificuldades de inserção dessas pessoas nos postos de trabalho formal. 
CRUZ, B. de P. A.; ROSS, S. D. The Buycott intention analyzed from sexual orientation and religion: The $\mathrm{O}$ Boticario’s Brazilian case. Almanaque Multidisciplinar de Pesquisa, v. 1, n. 1, Artigo Especial. 2016. Disponível em: http: / / publicacoes.unigranrio.edu.br/index. $\mathrm{php} / \mathrm{amp} / \mathrm{article} / \mathrm{view} / 4004$. Acesso em 30 Ago. 2018.

CONCETTA, M.; COUTO, C.. Sou barista. São Paulo: Editora SENAC, 2013.

REZENDE, J. C.; CHAGAS, S. J. R.; SILVA, V. A.; CARVALHO, G. R.; BOTELHO, C. E. Modos de consumo da bebida do café. In.: REIS, P. R.; CUNHA, R. L. da; CARVALHO, G. R. Café arábica: da pós colheita ao consumo. Vol. 2. Lavras: U.R.EPAMIG, 2011.

NASSIF, W.; ROSSI, G. B.; GARCIA, M. N.; BAZANINI, R. The Coffee Shop Influence on Coffee Consumption in the City of Sao Paulo. Revista Brasileira de Gestão de Negócios, v. 7, n. 19, 21-35, 2005. DOI: https: / / doi.org/10.7819/ rbgn.v7i19.47.

DPASCHOAL, L. N.. Aroma de CaféGuia Prático para Apreciadores de Café. Ed.Fund. Educar Dpaschoal 2006.
Aborda, de maneira tangencial, como política e religião podem influenciar no boicote de consumidores a partir de políticos conservadores ou progressistas.

Apresenta aspectos gerais relacionados às características do café a ser servido para o consumidor. O livro discute toda a cadeia de suprimentos do café no Brasil. O capítulo aqui escolhido tem como objetivo apresentar os modos de consumo de café no país, discutindo questões relacionadas aos cafés especiais e suas principais características.

O texto apresenta resultados empíricos sobre atributos importantes para consumidores de café, tais como o sabor e aroma.

Discute os tipos de café especiais a partir do aroma e sabor, bem como algumas características específicas do café como a doçura, acidez e as notas cítricas, frutadas ou florais.

Fonte: Elaboração dos autores. 


\section{DADOS DOS AUTORES}

BRENO DE PAULA ANDRADE CRUZ brenocruz@gastronomia.ufrj.br Doutor em Administração pela FGV-EAESP

Instituição de vinculação: Universidade Federal do Rio de Janeiro Rio de Janeiro/RJ - Brasil Áreas de interesse em pesquisa: Marketing; Boicote do Consumidor; Gastronomia; Responsabilidade Social Corporativa; Pesquisa em Administração.

INJC-UFRJ Av. Carlos Chagas, 373 Cidade Universitária Rio de Janeiro/RJ 21941-590

\section{RENATO AUGUSTO DA SILVA MONTEIRO}

\section{renatomonteiro@gastronomia.ufrj.br}

Doutor em Educação em Ciências e Saúde pela UFRJ

Instituição de vinculação: Universidade Federal do Rio de Janeiro

Rio de Janeiro/RJ - Brasil

Áreas de interesse em pesquisa: Alimentação; Bebidas; Consumo. 